\title{
Synthesis of Monophosphines Directly from White Phosphorus
}

\author{
Daniel J. Scott*, Jose Cammarata, Maximilian Schimpf and Robert Wolf* \\ Institute of Inorganic Chemistry, University of Regensburg, 93040 Regensburg, Germany \\ E-mail: daniel.scott@chemie.uni-regensburg.de, robert.wolf@ur.de
}

\begin{abstract}
Monophosphorus compounds are of enormous industrial importance due to the crucial roles they play in applications including pharmaceuticals, photoinitiators, and ligands for catalysis, among many others. White phosphorus $\left(\mathrm{P}_{4}\right)$ is the key starting material for the preparation of all such chemicals. However, current production depends upon indirect and inefficient, multistep procedures. Here, we report a simple, effective 'one pot' synthesis of a wide range of organic and inorganic monophosphorus species directly from $\mathrm{P}_{4}$. Reduction of $\mathrm{P}_{4}$ using tri- $n$ butyltin hydride and subsequent treatment with various electrophiles affords compounds that are of key importance for the chemical industry, and requires only mild conditions and inexpensive, easily handled reagents. Crucially, we also demonstrate facile and efficient recycling and ultimately even catalytic use of the tributyltin reagent, thereby avoiding the formation of significant Sn-containing waste. Accessible, industrially relevant products include the fumigant $\mathrm{PH}_{3}$, the reducing agent hypophosphorous acid, and the flame-retardant precursor tetrakis(hydroxymethyl)phosphonium chloride.
\end{abstract}

\section{Main Text}

White phosphorus $\left(\mathrm{P}_{4}\right)$ is one of the most important synthetic feedstocks for the modern chemical industry, ${ }^{1}$ and is produced on a scale of $>1 \mathrm{Mt}$ per year. The pyrophoric nature of $\mathrm{P}_{4}$ and its hazardous and energy-intensive synthesis from phosphate ores have prompted recent academic efforts to bypass this compound and instead use phosphate materials directly as synthetic precursors..$^{2-4}$ Other researchers have emphasized the need to develop more sustainable routes for the recycling and reuse of P-containing materials, which are otherwise 
lost as environmentally-hazardous wastes. ${ }^{2,5,6}$ However, despite these efforts, $\mathrm{P}_{4}$ remains the only industrially-viable precursor from which to prepare the vast majority of monophosphorus compounds, which find applications ranging from pharmaceuticals to chemical catalysts. ${ }^{7-9}$ Unfortunately, state-of-the-art industrial methods for the synthesis of these useful $\mathrm{P}_{1}$ species rely on indirect and correspondingly inefficient multi-step processes. The most common route (Fig. 1a) involves oxidation of $\mathrm{P}_{4}$ by toxic $\mathrm{Cl}_{2}$ gas to generate extremely corrosive $\mathrm{PCl}_{3} \cdot{ }^{10}$ Treatment with suitable nucleophiles then provides the desired products via substitution of chloride, with concomitant generation of chloride-containing waste. Alternatively, some $\mathrm{P}_{1}$ products can be generated by hydrophosphination of unsaturated organic compounds using $\mathrm{PH}_{3}$ gas. However, industrial-scale preparation of $\mathrm{PH}_{3}$ involves acid-catalysed or alkalimediated disproportionation of $\mathrm{P}_{4}$, which demands harsh reactions conditions and produces phosphorus oxyacid derivatives as stoichiometric byproducts (Figure 1). ${ }^{10}$

Recognition of the deficiencies of current routes for generating $\mathrm{P}_{1}$ products has prompted a strong desire to discover reactions that are capable of transforming $\mathrm{P}_{4}$ into these useful compounds directly, bypassing the need for isolation and manipulation of potentially hazardous intermediates. ${ }^{11-13}$ Unfortunately, such reactions are highly challenging, as they demand the complete and controlled cleavage of all six $\mathrm{P}-\mathrm{P}$ bonds of the $\mathrm{P}_{4}$ tetrahedron, alongside similarly orderly formation of up to 16 new P-E bonds. As a result, methods for the direct functionalisation of $\mathrm{P}_{4}$ remain exceedingly rare. ${ }^{14-24}$ The few known examples typically require highly forcing conditions and/or undesirable reagents (such as alkali metal reductants or elaborate transition metal - even precious metal - complexes) to ensure that the reactions are driven to completion, severely limiting their scope and practicality.

We describe herein a simple, efficient, 'one-pot' synthesis of various valuable and industrially relevant monophosphorus species from $\mathrm{P}_{4}$ using only commonly available reagents (Fig. $1 \mathrm{~b}$ ). The ubiquitous reducing agent tri- $n$-butyltin hydride $\left(\mathrm{Bu}_{3} \mathrm{SnH}\right)$ provides clean access to stannylsubstituted monophosphines in a process that is both very mild and highly versatile, being compatible with either photoinitiation or common chemical radical initiators. ${ }^{25-27}$ The product 
phosphines can be treated with organic and inorganic electrophiles to directly furnish commercially relevant $\mathrm{P}_{1}$ products. Furthermore, we show that the key $\mathrm{Bu}_{3} \mathrm{Sn}$ moiety can be readily recycled, and even employed catalytically, thereby mitigating any problems that might arise from formation of stoichiometric Sn-containing waste. Accessible products include $\mathrm{PH}_{3}$ (used as a fumigant, a reagent in the microelectronics industry, and a precursor to other organophosphorus compounds), ${ }^{10}$ hypophosphorous acid (used industrially as a reducing agent and synthetic intermediate), ${ }^{9,10,28}$ the tetrabenzylphosphonium salt $\left[\mathrm{Bn}_{4} \mathrm{P}\right] \mathrm{Br}$ (a Wittig chemistry precursor), ${ }^{29}$ and the phosphonium salt tetrakis(hydroxymethyl)phosphonium chloride (THPC, an important precursor to flame-retardant materials)..$^{9,30}$

\section{Results and Discussion}

\section{Hydrostannylation of $\mathrm{P}_{4}$}

The reactivity of $\mathrm{P}_{4}$ towards radical reagents potentially provides a viable route for the preparation of $\mathrm{P}_{1}$ products. However, in the few examples that have been reported to date, the elaborate strategies required to selectively access the necessary radical intermediates have severely limited their practicality and scope. ${ }^{17-22}$ We reasoned that the inexpensive, commercially available radical source $\mathrm{Bu}_{3} \mathrm{SnH}$ could serve as a convenient reagent for breaking apart the $\mathrm{P}_{4}$ molecule, since $\mathrm{Bu}_{3} \mathrm{SnH}$ readily generates formal $\mathrm{H} \cdot$ and $\mathrm{Bu}_{3} \mathrm{Sn} \cdot$ radicals upon photolysis or thermolysis in the presence of a radical initiator. ${ }^{31-34}$

In an initial experiment, $\mathrm{Bu}_{3} \mathrm{SnH}$ and $\mathrm{P}_{4}$ were combined in a 6:1 molar ratio in $\mathrm{PhMe}$ at room temperature. Gratifyingly, ${ }^{31} \mathrm{P}\left\{{ }^{1} \mathrm{H}\right\}$ NMR spectroscopic monitoring of the mixture showed clear consumption of $\mathrm{P}_{4}$ over the course of several days, with concomitant appearance of new upfield resonances at -288.7 and $-324.9 \mathrm{ppm}$ (major), and -242.0 and $-346.4 \mathrm{ppm}$ (trace), which collectively correspond to the products $\left(\mathrm{Bu}_{3} \mathrm{Sn}\right)_{n} \mathrm{PH}_{3-n}(n=0-3$, vide infra). Control experiments showed negligible reactivity when the reaction was repeated in the dark, suggesting a light-driven reaction. Indeed, when the reaction was performed under blue LED irradiation complete consumption of $\mathrm{P}_{4}$ was observed within $18 \mathrm{~h}$ (Figure 2 and Extended Data Figs. 1-4). Nearly identical product distributions were observed in various other common 
organic solvents ( $n$-hexane, $\mathrm{PhH}, \mathrm{Et}_{2} \mathrm{O}, \mathrm{THF}, \mathrm{DME} ;$ Extended Data Fig. 5 ) and an analogous outcome was also observed for the equivalent reaction of $\mathrm{P}_{4}$ with $\mathrm{Ph}_{3} \mathrm{SnH}$ (see Supplementary Method 2 for full details). ${ }^{35}$

The signal observed at $-242.0 \mathrm{ppm}$ is consistent with the formation of minor $\mathrm{PH}_{3}(1),{ }^{3}$ while the remaining resonances are assigned to the formation of new products $\mathrm{Bu}_{3} \mathrm{SnPH}_{2}$ $(2 ;-288.7 \mathrm{ppm}),{ }^{36}\left(\mathrm{Bu}_{3} \mathrm{Sn}\right)_{2} \mathrm{PH}(3 ;-324.9 \mathrm{ppm})$ and $\left(\mathrm{Bu}_{3} \mathrm{Sn}\right)_{3} \mathrm{P}(\mathbf{4} ;-346.4 \mathrm{ppm}) .{ }^{19}$ The observed upfield chemical shifts agree with previously-reported stannyl phosphines, ${ }^{37}$ and the presence of $\mathrm{P}-\mathrm{Sn}$ and $\mathrm{P}-\mathrm{H}$ bonds is confirmed by observation of ${ }^{117 / 119} \mathrm{Sn}$ satellites and of multiplicity in the proton-coupled ${ }^{31} \mathrm{P}$ spectra, respectively (see Methods section and Extended Data Figs. 2 and 3). ${ }^{16,38,39}$ The products obtained are consistent with complete, stoichiometric hydrostannylation of all six $\mathrm{P}-\mathrm{P}$ bonds of $\mathrm{P}_{4}$, as shown in Fig. 2a. The observed preference for $\mathrm{Bu}_{3} \mathrm{SnPH}_{2}$ and $\left(\mathrm{Bu}_{3} \mathrm{Sn}\right)_{2} \mathrm{PH}$ over $\mathrm{PH}_{3}$ and $\left(\mathrm{Bu}_{3} \mathrm{Sn}\right)_{3} \mathrm{P}$ is likely kinetic in origin (Supplementary Method 3) and may be attributable to steric factors that would disfavor installation of multiple $\mathrm{Bu}_{3} \mathrm{Sn}$ moieties on a single $\mathrm{P}$ atom. The major products can be separated by distillation under high vacuum $\left(105^{\circ} \mathrm{C}, 10^{-2}\right.$ mbar, see Supplementary Method 3$)$ to give $\mathrm{Bu}_{3} \mathrm{SnPH}_{2}(2 ; 31 \%)$ and $\left(\mathrm{Bu}_{3} \mathrm{Sn}\right)_{2} \mathrm{PH}\left(3 ; 45 \%\right.$, typically containing ca. $\left.10 \% \mathrm{Bu}_{3} \mathrm{SnPH}_{2} /\left(\mathrm{Bu}_{3} \mathrm{Sn}\right)_{3} \mathrm{P}\right)$ as colourless oils. Both are indefinitely stable when stored at $-35^{\circ} \mathrm{C}$ but undergo noticeable scrambling of their $\mathrm{H}$ and $\mathrm{Bu}_{3} \mathrm{Sn}$ ligands within a few days at room temperature, or more rapidly at elevated temperature (hence the minor impurities observed in samples of $\left(\mathrm{Bu}_{3} \mathrm{Sn}\right)_{2} \mathrm{PH}$ isolated by distillation). Notably, however, all three of the stannylated phosphines are highly stable in the presence of hydroxylic species such as $\mathrm{H}_{2} \mathrm{O}$ or alcohols. They are even moderately stable in the presence of $\mathrm{O}_{2}$ and can be exposed to air overnight at ambient temperature without significant decomposition (see Supplementary Method 4). This stands in stark contrast to other common " $\mathrm{P}^{3-\text { " }}$ synthons such as $\mathrm{P}\left(\mathrm{SiMe}_{3}\right)_{3}$ and represents a considerable practical advantage. $^{15}$

The precise mechanism of the $\mathrm{P}_{4}$ hydrostannylation reaction remains under investigation. Nevertheless, the use of light as an initiator clearly suggests a radical process, as radical chain 
reactions mediated by $\mathrm{Bu}_{3} \mathrm{SnH}$ are well established. ${ }^{31-34} \mathrm{~A}$ plausible mechanism is therefore outlined in Fig. 2b, in which each P-P bond is cleaved through initial attack of a $\mathrm{Bu}_{3} \mathrm{Sn}$. radical (for example, generated by photoelectron catalysis; Supplementary Method 1 ), ${ }^{40-42}$ followed by abstraction of $\mathrm{H} \cdot$ by the resulting $\mathrm{P}$-centred radical from another equivalent of $\mathrm{Bu}_{3} \mathrm{SnH}$, to regenerate $\mathrm{Bu}_{3} \mathrm{Sn}$. and continue the radical chain. Based on the proposed mechanism, it should also be possible to initiate hydrostannylation through use of a chemical (rather than photochemical) radical source. And, indeed, addition of $2.5 \mathrm{~mol} \%$ per $\mathrm{P}$ atom of the thermally activated radical initiator azobis(isobutyronitrile) (AIBN) was found to induce similarly efficient $\left(\mathrm{Bu}_{3} \mathrm{Sn}\right)_{x} \mathrm{PH}_{3-x}$ formation over a comparable timeframe in the dark, upon only very gentle heating (shorter reaction times could be used at higher temperatures; Supplementary Method 5). ${ }^{43}$ Comparable results were observed at more elevated temperatures using the related radical initiator 1,1'-azobis(cyclohexanecarbonitrile) (ACN; Supplementary Method 6). ${ }^{44}$ Similarly, addition of the stable radical 2,2,6,6-tetramethylpiperidinyloxyl (TEMPO) also led to slow hydrostannylation in the dark at room temperature (Supplementary Method 7; see also Supplementary Methods 8-11 for discussion of reactions involving excess TEMPO). ${ }^{45}{ }^{31} \mathrm{P}\left\{{ }^{1} \mathrm{H}\right\}$ NMR spectroscopic analysis of reaction mixtures at partial conversion revealed no resonances attributable to intermediate structures (see Supplementary Method 1, for example). However, we note that other $\mathrm{P}-\mathrm{P}$ bonded species such as $\mathrm{P}_{2} \mathrm{Ph}_{4}$ and cyclo$\mathrm{P}_{5} \mathrm{Ph}_{5}$ were also efficiently hydrostannylated under identical conditions (Supplementary Methods 12 and 13), ${ }^{46}$ suggesting that analogous $\mathrm{H} / \mathrm{Bu}_{3} \mathrm{Sn}$-substituted oligophosphorus structures are plausible.

\section{Functionalisation of $\left(\mathrm{Bu}_{3} \mathrm{Sn}\right)_{x} \mathrm{PH}_{3-x}$}

As with other phosphines, the $\mathrm{P}_{4}$ hydrostannylation products $\left(\mathrm{Bu}_{3} \mathrm{Sn}\right)_{x} \mathrm{PH}_{3-x}(x=1-3)$ were expected to display nucleophilic character at $\mathrm{P}$. To confirm this, the reactions of the major isolated products $\mathrm{Bu}_{3} \mathrm{SnPH}_{2}(2)$ and $\left(\mathrm{Bu}_{3} \mathrm{Sn}\right)_{2} \mathrm{PH}(3)$ with pivaloyl chloride $(t \mathrm{BuC}(\mathrm{O}) \mathrm{Cl})$ were investigated. It was anticipated that these could provide access to acyl-phosphorus linkages, which are a key structural motif in many industrially employed photoinitiators. ${ }^{47}$ While both the 
$\mathrm{P}-\mathrm{Sn}$ and $\mathrm{P}-\mathrm{H}$ bonds of the starting phosphines are potentially reactive, in this case the reactions were seen to lead to mild cleavage of the $\mathrm{P}-\mathrm{Sn}$ bonds only. Thus, the reaction of $\mathrm{Bu}_{3} \mathrm{SnPH}_{2}(2)$ with 1 equiv. $t \mathrm{BuC}(\mathrm{O}) \mathrm{Cl}$ was observed by ${ }^{31} \mathrm{P}\left\{{ }^{1} \mathrm{H}\right\}$ NMR spectroscopy to lead to the formation of a single major species, which was identified as the primary acyl phosphine tBuC(O) $\mathrm{PH}_{2}$ (5; Fig. 3(iii) and Supplementary Method 14) and could be isolated as a spectroscopically clean solution by simple trap-to-trap distillation. ${ }^{48}$ Similarly, reactions with $\left(\mathrm{Bu}_{3} \mathrm{Sn}\right)_{2} \mathrm{PH}(3)$ sequentially gave the mono- and bis-acyl phosphines $t \mathrm{BuC}(\mathrm{O}) \mathrm{P}(\mathrm{H}) \mathrm{SnBu}_{3}$ and $[t \mathrm{BuC}(\mathrm{O})]_{2} \mathrm{PH}$ as the major products (6 and 7, respectively; Fig. 3(iv),(v) and Supplementary Method 15). ${ }^{49}$

P-Sn bond cleavage could also be accomplished through addition of a Brønsted acid (Supplementary Method 16), leading to formation of $\mathrm{PH}_{3}$, which is employed industrially as a fumigant, in the synthesis of semiconductors, and as a precursor to many other $\mathrm{P}_{1}$ chemicals. ${ }^{10}$ Since in this case the same product was produced from both starting materials it was possible to combine $\mathrm{P}_{4}$ hydrostannylation and subsequent acidification into a simple one pot procedure, producing $\mathrm{PH}_{3}$ (1) directly and with high efficiency (Fig. 3(vi)).

Transformation of only the $\mathrm{P}-\mathrm{H}$ bonds of the hydrostannylation products could also be achieved. Reacting $\mathrm{Bu}_{3} \mathrm{SnPH}_{2}(2)$ or $\left(\mathrm{Bu}_{3} \mathrm{Sn}\right)_{2} \mathrm{PH}$ (3) with $\mathrm{Bu}_{3} \mathrm{SnOMe}$ led to selective formation of the fully stannylated phosphine $\left(\mathrm{Bu}_{3} \mathrm{Sn}\right)_{3} \mathrm{P}(4)$, thereby completing the set of isolable phosphines $\left(\mathrm{Bu}_{3} \mathrm{Sn}\right)_{x} \mathrm{PH}_{3-x}(x=1-3)$. The same product is again produced from both starting materials, and it was possible to combine $\mathrm{P}_{4}$ hydrostannylation and subsequent functionalisation into a simple one pot procedure in which $\mathbf{4}$ was isolated in excellent yield $(85 \%)$ without the need for isolation of any intermediates (Fig. 3(vii) and Supplementary Method 17).

In the above reactions $\mathrm{Bu}_{3} \mathrm{SnPH}_{2}$ and $\left(\mathrm{Bu}_{3} \mathrm{Sn}\right)_{2} \mathrm{PH}$ behave as formal sources of " $\left[\mathrm{H}_{2} \mathrm{P}\right]^{-}$", "[HP] $]^{2-", ~ " ~}\left[\mathrm{Bu}_{3} \mathrm{SnP}\right]^{2-"}$ and "[$\left.\left(\mathrm{Bu}_{3} \mathrm{Sn}\right)_{2} \mathrm{P}\right]^{-"}$. Also of great interest, however, are reactions in which

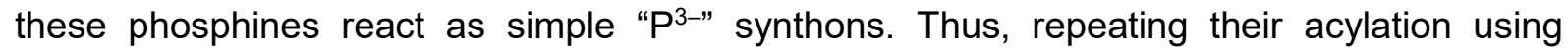
$t \mathrm{BuC}(\mathrm{O}) \mathrm{Cl}$ (vide supra) in the presence of a suitable base led to successful cleavage of both 
$\mathrm{P}-\mathrm{Sn}$ and $\mathrm{P}-\mathrm{H}$ bonds, and clean formation of the tertiary product $\mathrm{P}(\mathrm{C}(\mathrm{O}) \mathrm{tBu})_{3}(\mathbf{8}) .{ }^{50}$ Again, because the same compound is produced regardless of the starting phosphine, it was possible to access this species in an efficient, one pot manner directly from $\mathrm{P}_{4}$, and this reaction could be easily generalised to a variety of other acid chlorides substrates $(R C(O) C l, R=P h, i P r, C y$, Bu, Me; 9-13; Fig. 3(viii) and Supplementary Methods 18-23). ${ }^{51}$

Alternatively, in-situ treatment of the hydrostannylation products with benzyl bromide $(\mathrm{BnBr})$ under gentle heating led to selective formation of the corresponding fully alkylated phosphonium salt, [ $\left.\mathrm{Bn}_{4} \mathrm{P}\right] \mathrm{Br}$ (14), which is a precursor for useful Wittig chemistry (Fig. 4(ii) and Supplementary Method 24). ${ }^{29}$ As for the previous acylation reactions, in the absence of base the formation of $\mathbf{1 4}$ is proposed to proceed through functionalisation of $\mathrm{P}-\mathrm{Sn}$ bonds only, ${ }^{52}$ with $\mathrm{P}-\mathrm{H}$ bonds ultimately sequestered in the form of $\mathrm{PH}_{3}$ (Extended Data Fig. 6). In the presence of base, productive functionalisation of the $\mathrm{P}-\mathrm{H}$ bonds could also be achieved, leading to very efficient incorporation of $\mathrm{P}$ (Fig. 4(iii)). An analogous reaction using $\mathrm{EtBr}$ could also be used to obtain the ethyl-substituted salt [Et 4 P]Br (15; Fig. 4(iv) and Supplementary Method 25; for further reactions with organic halide substrates see Supplementary Methods 26-28).

Formaldehyde is also a suitable $C$-centred electrophile for reaction with the crude hydrostannylation product mixture..$^{53}$ Such reactions result in hydroxymethyl-substituted phosphines which possess specific industrial importance. Most notably, salts of the tetrakis(hydroxymethyl)phosphonium cation, $\left[\left(\mathrm{HOCH}_{2}\right)_{4} \mathrm{P}\right] \mathrm{X}\left(\mathrm{THPC}, \mathrm{X}=\mathrm{Cl}\right.$; THPS, $\mathrm{X}=1 / 2 \mathrm{SO}_{4}$ ) are used to prepare flame retardant materials through the $\mathrm{PROBAN}^{\circledR}$ process (THPC). ${ }^{9}$ They are also employed as microbicides for water treatment (THPS), and as precursors to other valuable $\mathrm{P}_{1}$ chemicals via extrusion of $\mathrm{CH}_{2} \mathrm{O}^{30}$ Treatment of the in situ-generated $\left(\mathrm{Bu}_{3} \mathrm{Sn}\right)_{x} \mathrm{PH}_{3-x}$ mixture with paraformaldehyde in $\mathrm{EtOH}$ provided good conversion to the parent phosphine $\left(\mathrm{HOCH}_{2}\right)_{3} \mathrm{P}(\mathrm{THP}, 16)$, which is conventionally produced by dealkylation of THPC, ${ }^{9}$ and is also used as a synthetic $P_{1}$ precursor, as well as a water-soluble ligand for transition metals. ${ }^{54}$ This could be isolated directly (Fig. 4(v) and Supplementary Method 29), or quenched with $\mathrm{HCl}$ to furnish THPC (17) in one pot and good yield following a simple workup (Fig. 4(vi) 
and Supplementary Method 30). Notably, excellent yields of THPC were also obtained when the initial hydrostannylation step was already performed in $\mathrm{EtOH}$ in the presence of paraformaldehyde, or when hydrostannylation was achieved using AIBN instead of light $(82 \%$ and $87 \%$ yield, respectively; Supplementary Methods 31 and 32). The latter procedure could conveniently be used to prepare THPC on over gram scale $(3.3 \mathrm{~g}, 87 \%$; Supplementary Method 33). Alternatively, quenching THP through exposure to air provided direct access to the corresponding phosphine oxide $\left(\mathrm{HOCH}_{2} \mathrm{P}\right)_{3} \mathrm{PO}(\mathrm{THPO}, 18)$, also in good isolated yield (Fig. 4(vii) and Supplementary Method 34). Like THPC, THPO has been used for the preparation of flame-retardant materials. ${ }^{55}$

Oxidation of the $\left(\mathrm{Bu}_{3} \mathrm{Sn}\right)_{x} \mathrm{PH}_{3-x}$ mixture in the absence of paraformaldehyde was also investigated, and treatment with $\mathrm{H}_{2} \mathrm{O}_{2}$ was found to selectively furnish partially oxidised hypophosphorous acid $\left(\mathrm{H}_{2} \mathrm{P}(\mathrm{O}) \mathrm{OH}, \mathrm{HPA}, 19\right)$ after workup (Fig. 4(viii) and Supplementary Method 35), alongside minor amounts $(<10 \%)$ of the known HPA oxidation product $\mathrm{HP}(\mathrm{O})(\mathrm{OH})_{2}$. In comparison, direct oxidation of $\mathrm{P}_{4}$ using peroxide reagents is known to be much less selective.$^{56} \mathrm{HPA}$ is another important $\mathrm{P}_{1}$ precursor, used to prepare phosphinic acid derivatives (e.g. Cyanex ${ }^{\circledR}$, used in metal separation processes), ${ }^{9}$ and is also employed industrially as a reductant (e.g. for electroless Nickel plating) ${ }^{28}$

\section{$\mathrm{Bu}_{3} \mathrm{Sn}$ regeneration and recycling}

Having established the ability of $\mathrm{Bu}_{3} \mathrm{SnH}$ to efficiently mediate the direct transformation of $\mathrm{P}_{4}$ into various useful and industrially relevant monophosphorus species, we became interested in the possibility of recovering and/or recycling the key $\mathrm{Bu}_{3} \mathrm{~S} n$ moiety. ${ }^{57}$ Such recycling would bypass any net formation of Sn-containing waste and could also provide a first step towards the development of catalytic reactions, which are all but unknown for $\mathrm{P}_{4}$ (vide infra). ${ }^{21-24}$ Fortunately, the $\mathrm{Bu}_{3} \mathrm{Sn}$ moiety is relatively robust, and in the above reactions is ultimately incorporated into a byproduct of the type $\mathrm{Bu}_{3} \mathrm{SnX}\left(\mathrm{X}=\mathrm{OR}\right.$ or halide, $\mathrm{R}=\mathrm{Bu}_{3} \mathrm{Sn}$ or alkyl) that is easily separated from the target product. For example, $\mathrm{Bu}_{3} \mathrm{SnCl}(20)$ could be recovered in high yield and with minimal effort from the syntheses of THPC and HPA by a simple extraction 
procedure after the reaction mixture was quenched with $\mathrm{HCl}$ (Fig. 5a). Transformation of $\mathrm{Bu}_{3} \mathrm{SnCl}$ into $\mathrm{Bu}_{3} \mathrm{SnH}$ is well established and can be achieved by various means (either directly or via facile hydrolysis or alcoholysis to $\mathrm{Bu}_{3} \mathrm{SnOR}$ ), commonly with near-quantitative conversions and excellent isolated yields (up to $95 \%$ ). ${ }^{58}$ Combination of any of these methods with the above reactions thus provides a simple and efficient synthetic cycle that does not produce any stoichiometric Sn-containing byproducts (Fig. 5b).

Although any known method could be employed for the regeneration of $\mathrm{Bu}_{3} \mathrm{SnH}$, especially attractive is the reaction of $\mathrm{Bu}_{3} \mathrm{SnOR}$ under mild conditions with polymethylhydrosiloxane (PMHS), a benign, stable and inexpensive polymeric reductant (Fig. 5c). ${ }^{59,60}$ In particular, it was anticipated that use of such a gentle method might allow generation of $\mathrm{Bu}_{3} \mathrm{SnH}$ to be combined with subsequent $\mathrm{P}_{4}$ functionalisation in a single reaction step (in a similar manner to $\mathrm{Bu}_{3} \mathrm{SnH}$-mediated reduction of some organic substrates), ${ }^{61}$ further simplifying the synthetic cycle. And, indeed, hydrostannylation of $\mathrm{P}_{4}$ could be successfully achieved upon replacement of $\mathrm{Bu}_{3} \mathrm{SnH}$ with a mixture of $\mathrm{Bu}_{3} \mathrm{SnOMe}$ or $\left(\mathrm{Bu}_{3} \mathrm{Sn}\right)_{2} \mathrm{O}$ and PMHS (Supplementary Methods 36-38). These tandem reactions could be fed directly into subsequent steps, as illustrated by the synthesis of THPC, which was isolated in one pot and excellent yields starting from both $\mathrm{Bu}_{3} \mathrm{SnOMe}$ and $\left(\mathrm{Bu}_{3} \mathrm{Sn}\right)_{2} \mathrm{O}$ (Fig. 6a,b and Supplementary Methods 39-40). The $\mathrm{Bu}_{3} \mathrm{SnCl}$ by-product of the latter reaction could again be separated from the target product by simple extraction, alongside PMHS-derived by-products. In fact, it was found that this 'crude' $\mathrm{Bu}_{3} \mathrm{SnCl}$ could be employed directly as a $\mathrm{Bu}_{3} \mathrm{Sn}$ source for further $\mathrm{P}_{4}$ functionalisation, without the need for separation of the pure compound. Thus, after simple stirring over aqueous $\mathrm{Na}_{2} \mathrm{CO}_{3}$ (to convert back to $\left.\left(\mathrm{Bu}_{3} \mathrm{Sn}\right)_{2} \mathrm{O}\right)$ this unpurified material was added to a fresh reaction mixture, ultimately yielding a new batch of THPC in good yield (albeit reduced somewhat relative to the first 'cycle'; Fig. 6c).

\section{Catalytic use of $\mathrm{Bu}_{3} \mathrm{Sn}$}

Having established the viability of a synthetic cycle that is closed in $\mathrm{Bu}_{3} \mathrm{Sn}$, attention was finally turned to the development of a catalytic process. ${ }^{61}$ Such reactions represent a longstanding 
but almost entirely unmet goal in the field of $\mathrm{P}_{4}$ activation. ${ }^{21-24}$ Reducing the amount of the $\mathrm{Bu}_{3} \mathrm{SnX}$ reagent employed should also further minimize any risks associated with its use. Gratifyingly, the formation of THP en route to THPC could be achieved using only a catalytic quantity $\left(8.25\right.$ mol\% per $\mathrm{P}$ atom) of $\mathrm{Bu}_{3} \mathrm{SnOMe}$, with turnover numbers (TONs) greater than ten achievable after only minor modification of the stoichiometric procedures (Fig. 7 and Supplementary Method 41; see Extended Data Fig. 7 for an outline catalytic cycle). Only one other example of catalytic $\mathrm{P}-\mathrm{C}$ bond formation from $\mathrm{P}_{4}$ is known, which is strictly limited to $\mathrm{P}-$ C(aryl) bonds. ${ }^{21,22}$

\section{Conclusions}

We have developed a practical, versatile method for the direct transformation of $\mathrm{P}_{4}$ into useful monophosphorus species, mediated by the readily-available triorganotin(IV) moiety $\mathrm{Bu}_{3} \mathrm{Sn}$. This method can be used to prepare diverse monophosphorus compounds which are of clear industrial relevance in areas such as flame retardants, photoinitiators and fumigants. Both organic and inorganic phosphorus products are accessible in a 'one pot' manner without the need for wasteful or time-consuming isolation of intermediates, and the reactions require only inexpensive, commercially available reagents. Importantly, facile recovery and recycling of the $\mathrm{Bu}_{3} \mathrm{Sn}$ moiety has been achieved, which prevents the formation of significant $\mathrm{Sn}$-containing waste. Indeed, the $\mathrm{Bu}_{3} \mathrm{Sn}$ moiety may even be employed in a truly catalytic fashion, as illustrated for the synthesis of the important industrial precursor THPC. This catalytic use of the tri-n-butyltin reagent further minimises any risks associated with the use of organotin compounds. The use of a p-block element catalyst to produce a highly useful organophosphorus compound was previously unknown, and our results thus suggest that the conspicuous shortage of catalytic methods of the transformation of $\mathrm{P}_{4}$ can be overcome. While our research has so far focused on commercially available butyl-substituted tin derivatives, the practical and conceptual simplicity of the approach described herein promises ready extension to a much wider range of radical sources, potentially even including those based on other 
p-block elements. We therefore anticipate that the reported method will have a major impact on the future synthesis of monophosphorus compounds in laboratory and industrial settings.

\section{References (main text)}

1. Gleason, W. An Introduction to phosphorus: history, production, and application. JOM 59, 17-19 (2007).

2. Geeson, M. B. \& Cummins, C. C. Let's make white phosphorus obsolete. ACS Cent. Sci. 6, 848-860 (2020).

3. Geeson, M. B. \& Cummins, C. C. Phosphoric acid as a precursor to chemicals traditionally synthesized from white phosphorus. Science 359, 1383-1385 (2018).

4. Geeson, M. B., Ríos, P., Transue, W. J. \& Cummins, C. C. Orthophosphate and sulfate utilization for $C-E(E=P, S)$ bond formation via trichlorosilyl phosphide and sulphide anions. J. Am. Chem. Soc. 141, 6375-6384 (2019).

5. Scholz, R. W., Roy, A. H., Brand, F. S., Hellums, D. \& Ulrich, A. E. Sustainable Phosphorus Management (Springer, 2014)

6. Ohtake, H. \& Tsuneda, S. Phosphorus Recovery and Recycling (Springer, 2019).

7. Corbridge, D. E. C. Phosphorus 2000. Chemistry, Biochemistry and Technology (Elsevier, 2000).

8. Diskowski, H. Hofmann, T. "Phosphorus" in Ullmann's encyclopedia of industrial chemistry (Wiley, 2000).

9. Svara, J., Weferling, N. \& Hofmann, T. "Phosphorus Compounds, Organic" in Ullmann's encyclopedia of industrial chemistry (Wiley, 2006).

10. Bettermann, G., Krause, W., Riess, G. \& Hofmann, T. "Phosphorus Compounds, Inorganic" in Ullmann's encyclopedia of industrial chemistry (Wiley, 2000). 
11. Cossairt, B. M., Piro, N. A. \& Cummins, C. C. Early-transition-metal-mediated activation and transformation of white phosphorus. Chem. Rev. 110, 4164-4177 (2010).

12. Caporali, M., Gonsalvi, L., Rossin, A. \& Peruzzini, M. $\mathrm{P}_{4}$ activation by late-transition metal complexes. Chem. Rev. 110, 4178-4235 (2010).

13. Scheer, M., Balázs, G. \& Seitz, A. $P_{4}$ activation by main group elements and compounds. Chem. Rev. 110, 4236-4256 (2010).

14. Xu, L., Chi, Y., Du, S., Zhang, W.-X. \& Xi, Z. Angew. Chem. Int. Ed. 55, 9187-9190 (2016).

15. Becker, G. et al. Tris(trimethylsilyl)phosphine and lithium bis(trimethylsilyl)phosphide bis (tetrahydrofuran). Inorg Synth. 27, 243-349 (1990).

16. Bhattacharrya, K. X., Dreyfuss, S., Saffon-Merceron, N. \& Mézailles, N. P4 functionalization by hydrides: direct synthesis of P-H bonds. Chem. Comm. 52, 5179$5182(2016)$.

17. Barton, D. H. R. \& Zhu, J. Elemental white phosphorus as a radical trap: a new and general route to phosphonic acids. J. Am. Chem. Soc. 115, 2071-2072 (1993).

18. Barton, D. H. R. \& Embse, R. A. V. The invention of radical reactions. Part 39. The reaction of white phosphorus with carbon-centred radicals. An improved procedure for the synthesis of phosphonic acids and further mechanistic insights. Tetrahedron. 54, 12475-12496 (1998).

19. Cossairt, B. M. \& Cummins, C. C. Radical synthesis of trialkyl, triaryl, trisilyl and tristannyl phosphines from $\mathrm{P}_{4}$. New J. Chem. 34, 1533-1536 (2010).

20. Ghosh, S. K., Cummins, C. C. \& Gladysz, J. A. A direct route from white phosphorus and fluorous alkyl and aryl iodides to the corresponding trialkyl- and triarylphosphines. Org. Chem. Front. 5, 3421-3429 (2018). 
21. Lennert, $U$. et al. Direct catalytic transformation of white phosphorus into arylphosphines and phosphonium salts. Nat. Catal. 2, 1101-1106 (2019).

22. Arockiam, P. B. et al. Versatile visible-light-driven synthesis of unsymmetrical phosphines and phosphonium salts. Chem. Eur. J. 10.1002/chem.202002646.

23. Lu, G. et al. Visible-light-mediated direct synthesis of phosphorotrithioates as potent anti-inflammatory agents from white phosphorus. Org. Chem. Front. 6, 190-194 (2019).

24. Riesel, L., Kant, M. \& Helbing, R. Zur Direktsynthesevon Trialk(ar)ylphosphiten und trithiophosphiten aus elementarem Phosphor. Z. Anorg. Allg. Chem. 580, 217-223 (1990).

25. Mathiasch, B. \& Dräger M. Decamethyl- $1 \lambda^{3}, 4 \lambda^{3}$-diphospha-2,3,5,6,7pentastannabicyclo[2.2.1]heptane, a bicyclic compound rich in tin. Angew. Chem. Int. Ed. 17, 767-768 (1978).

26. Mathiäsch, B. Pentakis(dimethylzinn)diphosphid, Struktur und Kernresonanzspektren eines zinnreiches Bicyclus. J. Organomet. Chem. 165, 295-301 (1979).

27. Dräger, M. \& Mathiasch, B. Dodecamethyl- $1 \lambda^{3}, 4 \lambda^{3}$-diphospha-2,3,5,6,7,8hexastannabicyclo[2.2.2]octane, a highly symmetrical cage molecule. Angew. Chem. Int. Ed. 20, 1029-1030 (1981).

28. Brenner, A. \& Riddell, G. Nickel plating on steel by chemical reduction. J. Res. Nat. Bur. Stand. 37, 31-34 (1946).

29. Schmidbaur, H., Deschler, U., Milewski-Mahrla, B. \& Zimmer-Gasser, B. Phosphoniumbenzylide und Alkali-[phosphoniumbis(benzylide)]:Beispiele für salzfreie Ylide und korrespondierende Alkalikomplexe. Chem. Ber. 114, 608-619 (1981).

30. Vullo, W. J. Hydroxymethyl replacement reactions of tetrakis(hydroxymethyl)phosphonium chloride. Ind. Eng. Chem. Proc. Res. Dev. 5, 346349 (1966). 
31. Kuivila, H. Reduction of organic compounds by organotin hydrides. Synthesis 1970 , 499-509 (1970).

32. Neumann, W. P. Tri-n-butyltin hydride as reagent in organic synthesis. Synthesis 1987, 665-683 (1987).

33. Pereyre, M., Quintard, J.-P. \& Rahm, A. Tin in organic synthesis. (Butterworths, 1987).

34. Rajanbabu, T. V., Bulman Page, P. C. \& Buckley, B. R. "Tri-n-butylstannane" in Encyclopedia of reagents for organic synthesis (Wiley, 2004).

35. Cummins, C. C. et al. The stannylphosphide anion reagent sodium bis(triphenylstannyl) phosphide: synthesis, structural characterization, and reactions with indium, tin, and gold electrophiles. Inorg. Chem. 53, 3678-3687 (2014).

36. Norman, A. D. The synthesis of (trimethylstannyl)phosphine: the observation of phosphorus-tin nuclear spin-spin coupling. J. Organometal. Chem. 28, 81-86 (1971).

37. Schumann, H. Organogermyl, organostannyl, and organoplumbyl phosphines, arsines, stibines, and bismuthines. Angew. Chem. Int. Ed. 8, 937-950 (1969).

38. Peruzzini, M., de los Rios, I., Romerosa, A. \& Vizza, F. Metal-assisted P-H bond formation: a step towards the hydrogenation of white phosphorus. Eur. J. Inorg. Chem. 593-608 (2001).

39. Gafurov, Z. N., Kagilev, A. A., Kantyukov, A. O., Sinyashin, O. G. \& Yakharov, D. G. Hydrogenation reaction pathways in chemistry of white phosphorus. Pure Appl. Chem. 91, 797-810 (2019).

40. Chanon, M. \& Tobe, M. L. ETC: a mechanistic concept for inorganic and organic chemistry. Angew. Chem. Int. Ed. 21, 1-23 (1982).

41. Chanon, K. Electron-transfer catalysis applied to organometallics. Part I. Application to the activation of $\mathrm{Csp}_{3}-\mathrm{X}$ bonds and other $\sigma$-bonded species. Bull. Soc. Chim. Fr. 1982 , 197-238 (1982). 
42. Julliard, M. \& Chanon, M. Photoelectron-transfer catalysis: its connections with thermal and electrochemical analogues. Chem. Rev. 83, 425-506 (1983).

43. Simpkins, N. S. "Azobisisobutyronitrile" in Encyclopedia of reagents for organic synthesis (Wiley, 2001).

44. Kates, S. A. \& Albericio, F. "1,1'-Azobis-1-cyclohexanenitrile" in Encyclopedia of reagents for organic synthesis (Wiley, 2001).

45. Montanari, F. et al. "2,2,6,6-Tetramethylpiperidin-1-oxyl" in Encyclopedia of reagents for organic synthesis (Wiley, 2016).

46. Sato, A., Yorimitsu, H. \& Oshima, K. Radical phosphination of organic halides and alkyl imidazole-1-carbothioates. J. Am. Chem. Soc. 128, 4240-4241 (2006).

47. Huber, A. et al. Phosphorus-functionalized bis(acyl)phosphane oxides for surface modification. Angew. Chem. Int. Ed. 51, 4648-4652 (2012).

48. Becker, G., Rössler, M. \& Uhl, W. Acyl- und alkylidenphosphane. XII. Synthese und Eigenschaften des 2,2-Dimethylpropionylphosphans und einiger Derivate. Z. Anorg. Allg. Chem. 473, 7-19 (1981).

49. Becker, G., Rössler, M. \& Uhl, G. Acyl- und Alkylidenphosphane. XX. Bis(2,2dimethylpropionyl)phosphan und Bis(2,2dimethylpropionyl)phosphide. Z. Anorg. Allg. Chem. 495, 73-88 (1982).

50. Becker, G. Bildung und Eigenschaften von Acylphosphinen. II. Verbindungen aus der Reaktion von Tris(trimethylsilyl)phosphin mit Pivaloylchlorid. Z. Anorg. Allg. Chem. 430, 66-76 (1977).

51. Verlhac, J.-B. \& Quintard, J.-P. N,N-dialkylaminomethyltributyltins as precursors of (N,N-dialkylaminomethyl) ketones. Tetrahedron Lett. 27, 2361-2364 (1986). 
52. Vaillard, S. E., Mück-Lichtenfeld, C., Grimme, S. \& Studer A. Homolytic substitution at phosphorus for the synthesis of alkyl and aryl phosphanes. Angew. Chem. Int. Ed. 46, 6533-6536 (2007).

53. Borger, J. E., Ehlers, A. W., Slootweg, J. C. \& Lammertsma, K. Functionalization of $P_{4}$ through direct P-C bond formation. Chem. Eur. J. 23, 11738-11746 (2017).

54. Katti, K. V., Gali, H., Smith, C. J. \& Berning, D. E. Design and development of functionalized water-soluble phosphines: catalytic and biomedical implications. Acc. Chem. Res. 32, 9-17 (1999).

55. Chen, M.-J. et al. Inherently flame-retardant flexible polyurethane foam with a low content of phosphorus-containing cross-linking agent. Ind. Eng. Chem. Res. 53, 1160$1171(2014)$.

56. Akbayeva, D. N., Faisova, F. Kh., Abdreimova, R. R. \& Peruzzini, M. Oxidation of white phosphorus by peroxides in aqueous and alcoholic solutions: mechanistic aspects and catalytic studies. J. Mol. Catal. A 267, 181-193 (2007).

57. Le Grognec, E., Chrétien, J.-M., Zammattio, F. \& Quintard, J.-P. Methodologies limiting or avoiding contamination by organotin residues in organic synthesis. Chem. Rev. 115, 10207-10260 (2015).

58. Tsangaris, J. M., Willem, R. \& Gielen, M. "Synthesis of M(IV) organometallic compounds, where $\mathrm{M}=\mathrm{Ge}, \mathrm{Sn}, \mathrm{Pb}$ " in Patai's chemistry of functional groups (Wiley, 2009).

59. Lawrence, N. J., Drew, M. D. \& Bushell, S. M. Polymethylhydrosiloxane: a versatile reducing agent for organic synthesis. J. Chem. Soc. Perkin Trans. $13381-3391$ (1999).

60. Hayashi, K., Iyoda, J. \& Shiihara, I. Reaction of organotin oxides, alkoxides and acyloxides with organosilicon hydrides. New preparative method of organotin hydrides. J. Organomet. Chem. 10, 81-94 (1967). 
61. Lipowitz, J. \& Bowman, S. A. Use of polymethylhydrosiloxane as a selective, neutral reducing agent for aldehydes, ketones, olefins, and aromatic nitro compounds. J. Org. Chem. 38, 162-165 (1973).

\section{Acknowledgements}

We thank O. Garcia Mancheño, K. Zeitler, and Jan J. Weigand for valuable discussions. Funding by the European Research Council (ERC CoG 772299) and the Alexander von Humboldt foundation (postdoctoral fellowship for D.J.S.) is gratefully acknowledged.

Correspondence and requests for materials should be addressed to D.J. S. or R.W.

\section{Author contributions}

D.J.S. developed the hydrostannylation procedures, developed initial procedures for formation of final products, and performed mechanistic studies. D.J.S. and J.C. optimised the synthesis, isolation and purifications of products at increased scale, and the recovery and recycling of $\mathrm{Bu}_{3} \mathrm{Sn}$-based byproducts. D.J.S. and M.S. developed the catalytic synthesis of THPC. D.J.S. and R.W. conceived, oversaw and directed the project. D.J.S. prepared the manuscript. All authors discussed the results and commented on the manuscript.

\section{Competing interests}

A patent covering all of the results described herein has been filed (as of 13/02/2020) by the University of Regensburg (EP 20157 197.3; D.J.S., R.W. inventors). The authors declare no other conflicts of interest. 


\section{Figures}
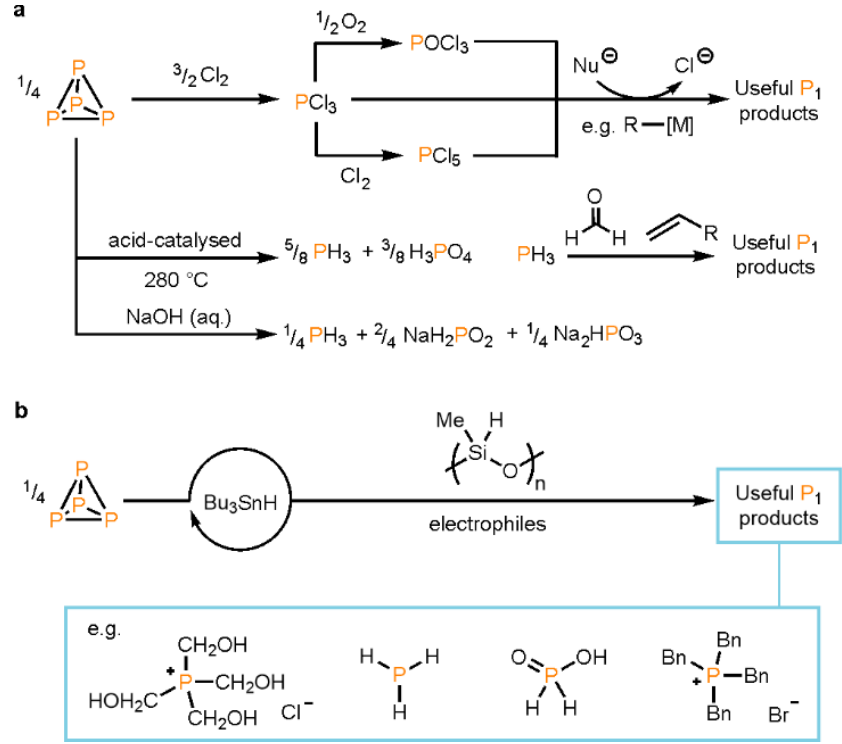

Figure 1. Strategies for the transformation of $\mathrm{P}_{4}$ into monophosphorus products. a, Current stateof-the-art methods, which involve either: oxidation with $\mathrm{Cl}_{2}$ (to generate $\mathrm{PCl}_{3}$, which may be oxidized further to $\mathrm{PCl}_{5}$ or $\mathrm{POCl}_{3}$ ) and subsequent reaction with nucleophiles; or base-induced or acid-catalysed disproportionation to form $\mathrm{PH}_{3}$, which is then used for hydrophosphination of unsaturated substrates. $\mathbf{b}$, The strategy reported herein, in which hydrostannylation of $\mathrm{P}_{4}$ using $\mathrm{Bu}_{3} \mathrm{SnH}$ is followed by reaction with electrophiles in a 'one pot' fashion. The Bu3SnH-derived byproducts can be recovered and used to regenerate $\mathrm{Bu}_{3} \mathrm{SnH}$ in a closed synthetic loop, using polymethylhydrosiloxane as a cheap and benign terminal reductant.

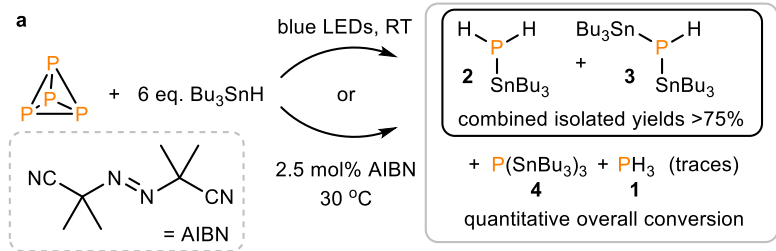

b

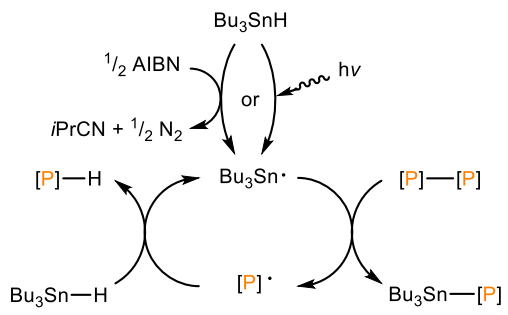

Figure 2. Hydrostannylation of $\mathbf{P}_{4}$. a, Stoichiometric reaction of $\mathrm{P}_{4}$ with $\mathrm{Bu} 3 \mathrm{SnH}$ to give products $\left(\mathrm{Bu}_{3} \mathrm{Sn}\right)_{x} \mathrm{PH}_{3-x}(x=0-3)$, initiated by either light or a chemical radical initiator. $\mathbf{b}, \mathrm{A}$ plausible radical chain 
mechanism for $\mathrm{P}_{4}$ hydrostannylation, where $[\mathrm{P}]-[\mathrm{P}]$ represents a generic $\mathrm{P}-\mathrm{P}$ bond. AlBN loading $(\mathrm{mol} \%)$ is defined per $\mathrm{P}$ atom.

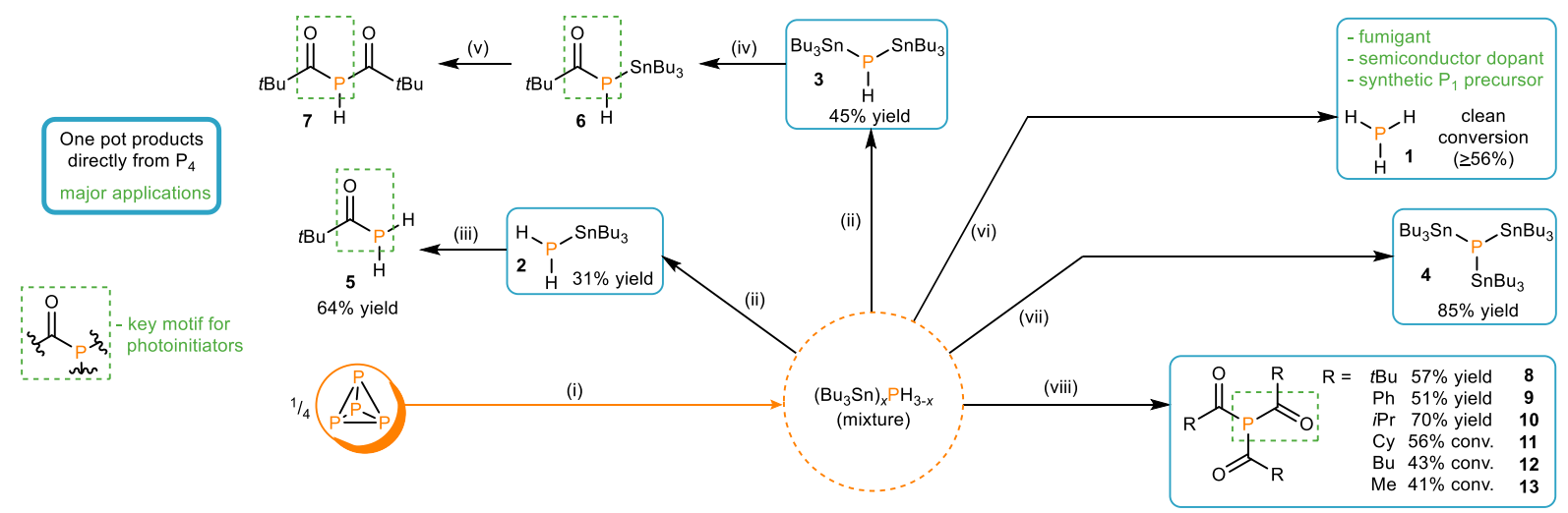

Figure 3. Functionalisation of phosphines $\left(\mathrm{Bu}_{3} \mathrm{Sn}\right)_{x} \mathrm{PH}_{3-x}$ and direct, 'one pot' functionalisation of

$\mathbf{P}_{4}$. Equivalents, equiv., are here defined per $\mathrm{P}$ atom. (i) Hydrostannylation of $\mathrm{P}_{4}$ using $\mathrm{Bu} 3 \mathrm{SnH}$ (from $\mathrm{P}_{4}$ : 1.56 equiv. $\mathrm{Bu}_{3} \mathrm{SnH}, \mathrm{PhMe}, 455 \mathrm{~nm}$ LEDs, RT, 16 h). (ii) Preparative separation of $\mathrm{Bu}_{3} \mathrm{SnPH}_{2}$ (2) and $\left(\mathrm{Bu}_{3} \mathrm{Sn}\right)_{2} \mathrm{PH}(3)$ (from crude $\left(\mathrm{Bu}_{3} \mathrm{Sn}\right)_{\times} \mathrm{PH}_{3-\mathrm{x}}$ : distillation, ca. $70{ }^{\circ} \mathrm{C}, 10^{-5} \mathrm{mbar}$ ). (iii) Monoacylation of $\mathrm{Bu}_{3} \mathrm{SnPH}_{2}$ (2) using $t \mathrm{BuC}(\mathrm{O}) \mathrm{Cl}$ (from $\mathrm{Bu}_{3} \mathrm{SnPH}_{2}$ : 0.95 equiv. tBuC(O)Cl, PhMe, dark, $\mathrm{RT}, 16 \mathrm{~h}$ ). (iv) Monoacylation of $\left(\mathrm{Bu}_{3} \mathrm{Sn}\right)_{2} \mathrm{PH}(3)$ using $t \mathrm{BuC}(\mathrm{O}) \mathrm{Cl}$ (from $\left(\mathrm{Bu} \mathrm{B}_{3} \mathrm{Sn}\right)_{2} \mathrm{PH}$ : 1 equiv. $\left.t \mathrm{BuC}(\mathrm{O}) \mathrm{Cl}, \mathrm{C}_{6} \mathrm{D}_{6}, \mathrm{RT}\right)$. (v) Double acylation of $\left(\mathrm{Bu}_{3} \mathrm{Sn}\right)_{2} \mathrm{PH}(3)$ using $t \mathrm{BuC}(\mathrm{O}) \mathrm{Cl}$ (from $\left(\mathrm{Bu}_{3} \mathrm{Sn}\right)_{2} \mathrm{PH}: 2$ equiv. $\left.t \mathrm{BuC}(\mathrm{O}) \mathrm{Cl}, \mathrm{C}_{6} \mathrm{D}_{6}, \mathrm{RT}\right)$. (vi) One pot, selective transformation of $\mathrm{P}_{4}$ into $\mathrm{PH}_{3}$ (1) (from crude $\left(\mathrm{Bu}_{3} \mathrm{Sn}\right) \times \mathrm{PH}_{3-\mathrm{x}}$ : 10 equiv. $\mathrm{HCl}(4.0 \mathrm{M}$ in 1,4-dioxane), $\mathrm{RT}, 1 \mathrm{~h}$ ). (vii) One pot synthesis of $\left(\mathrm{Bu}_{3} \mathrm{Sn}\right)_{3} \mathrm{P}(4)$ (from $\mathrm{P}_{4}: 1.5$ equiv. $\mathrm{Bu}_{3} \mathrm{SnH}, 1.5$ equiv. $\mathrm{Bu}_{3} \mathrm{SnOMe}, \mathrm{PhMe}, 455 \mathrm{~nm}$ LEDs, RT, $16 \mathrm{~h}$, then -PhMe, $100{ }^{\circ} \mathrm{C}, 16 \mathrm{~h}$ ). (viii) One pot synthesis of triacylphosphines $\mathrm{P}(\mathrm{C}(\mathrm{O}) t \mathrm{Bu})_{3}$ (8-13) (from $\mathrm{P}_{4}$ : 1.6 equiv. $\mathrm{Bu}_{3} \mathrm{SnH}$, PhMe, $455 \mathrm{~nm}$ LEDs, $\mathrm{RT}, 16 \mathrm{~h}$, then 4 equiv. $\mathrm{RC}(\mathrm{O}) \mathrm{Cl}, 1.5$ equiv. KHMDS $(\mathrm{R}=t \mathrm{Bu}, \mathrm{Ph})$ or $\mathrm{NEt}_{3}(\mathrm{R}=i \mathrm{Pr}, \mathrm{Cy}, \mathrm{Bu}, \mathrm{Me}), \mathrm{PhMe}$, dark, $\left.\mathrm{RT}, 16 \mathrm{~h}\right)$.

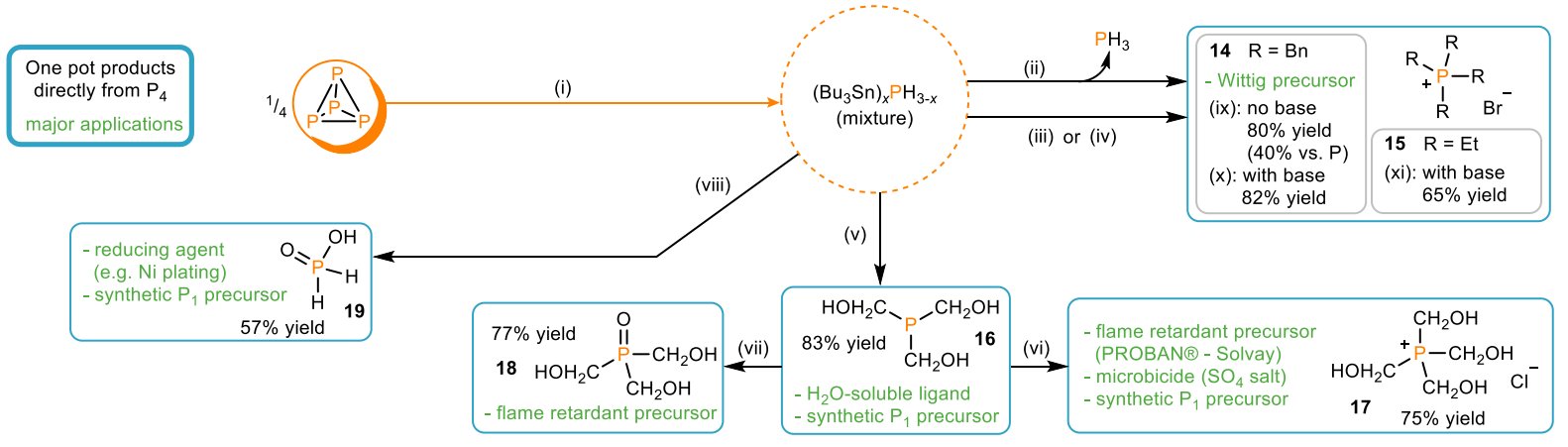

Figure 4. Further, direct, 'one pot' functionalisation of $\mathbf{P}_{\mathbf{4}}$. Equivalents, equiv., are here defined per $\mathrm{P}$ atom. (i) Hydrostannylation of $\mathrm{P}_{4}$ using $\mathrm{Bu}_{3} \mathrm{SnH}$ (from $\mathrm{P}_{4}$ : 1.56 equiv. $\mathrm{Bu}_{3} \mathrm{SnH}, \mathrm{PhMe}, 455 \mathrm{~nm}$ LEDs, 
$\mathrm{RT}, 16 \mathrm{~h}$ ). (ii) One pot synthesis of [ $\left.\mathrm{Bn}_{4} \mathrm{P}\right] \mathrm{Br}$ (14), without base (from $\mathrm{P}_{4}: 1.6$ equiv. $\mathrm{Bu}_{3} \mathrm{SnH}, \mathrm{PhMe}, 455$ nm LEDs, RT, $16 \mathrm{~h}$, then 10 equiv. $\mathrm{BnBr}, 60^{\circ} \mathrm{C}, 3 \mathrm{~d}$ ). (iii) One pot synthesis of $\left[\mathrm{Bn}{ }_{4} \mathrm{P}\right] \mathrm{Br}$ (14), with base (from $\mathrm{P}_{4}$ : 1.6 equiv. Bus $\mathrm{SnH}, \mathrm{PhMe}, 455 \mathrm{~nm}$ LEDs, RT, $16 \mathrm{~h}$, then 10 equiv. $\mathrm{BnBr}, 1$ equiv. KHMDS, $60{ }^{\circ} \mathrm{C}, 3 \mathrm{~d}$ ). (iv) One pot synthesis of $\left[\mathrm{Et}_{4} \mathrm{P}\right] \mathrm{Br}$ (15), with base (from $\mathrm{P}_{4}: 1.6$ equiv. $\mathrm{Bu}_{3} \mathrm{SnH}, \mathrm{PhMe}, 455$ $\mathrm{nm}$ LEDs, RT, $16 \mathrm{~h}$, then 5 equiv. EtBr, 2 equiv. KHMDS, $100{ }^{\circ} \mathrm{C}, 3 \mathrm{~d}$ ). (v) One pot synthesis of $\left(\mathrm{HOCH}_{2}\right)_{3} \mathrm{P}(\mathrm{THP}, 16)$ (from $\mathrm{P}_{4}: 1.6$ equiv. $\mathrm{Bu}_{3} \mathrm{SnH}, 3$ equiv. paraformaldehyde, $\mathrm{EtOH}, 455 \mathrm{~nm}$ LEDs, $\mathrm{RT}, 16 \mathrm{~h}$ ). (vi) One pot synthesis of $\left[\left(\mathrm{HOCH}_{2}\right)_{4} \mathrm{P}\right] \mathrm{Cl}$ (THPC, 17) (from $\mathrm{P}_{4}: 1.6$ equiv. Bu3 $\mathrm{SnH}, \mathrm{PhMe}, 455$ nm LEDs, RT, $16 \mathrm{~h}$, then -PhMe, EtOH, 12.5 equiv. paraformaldehyde, RT, $16 \mathrm{~h}$, then 10 equiv. $\mathrm{HCl}$ (4.0 M in 1,4-dioxane), RT, 2 h). (vii) One pot synthesis of $\left(\mathrm{HOCH}_{2}\right)_{3} \mathrm{PO}$ (THPO, 18) (from crude THP: $\mathrm{PhMe} / \mathrm{H}_{2} \mathrm{O}$, air, $90{ }^{\circ} \mathrm{C}, 16$ h). (viii) One pot synthesis of $\mathrm{H}_{2} \mathrm{P}(\mathrm{O}) \mathrm{OH}$ (HPA, 19) (from $\mathrm{P}_{4}$ : 1.6 equiv. $\mathrm{Bu}_{3} \mathrm{SnH}, \mathrm{PhMe}, 455 \mathrm{~nm}$ LEDs, RT, $16 \mathrm{~h}$, then 10 equiv. $\mathrm{H}_{2} \mathrm{O}_{2}$ (35\% aq.), RT, 30 min, then $\mathrm{H}_{2} \mathrm{O}, 2.5$ equiv. $\mathrm{HCl}(4.0 \mathrm{M}$ in 1,4-dioxane)).

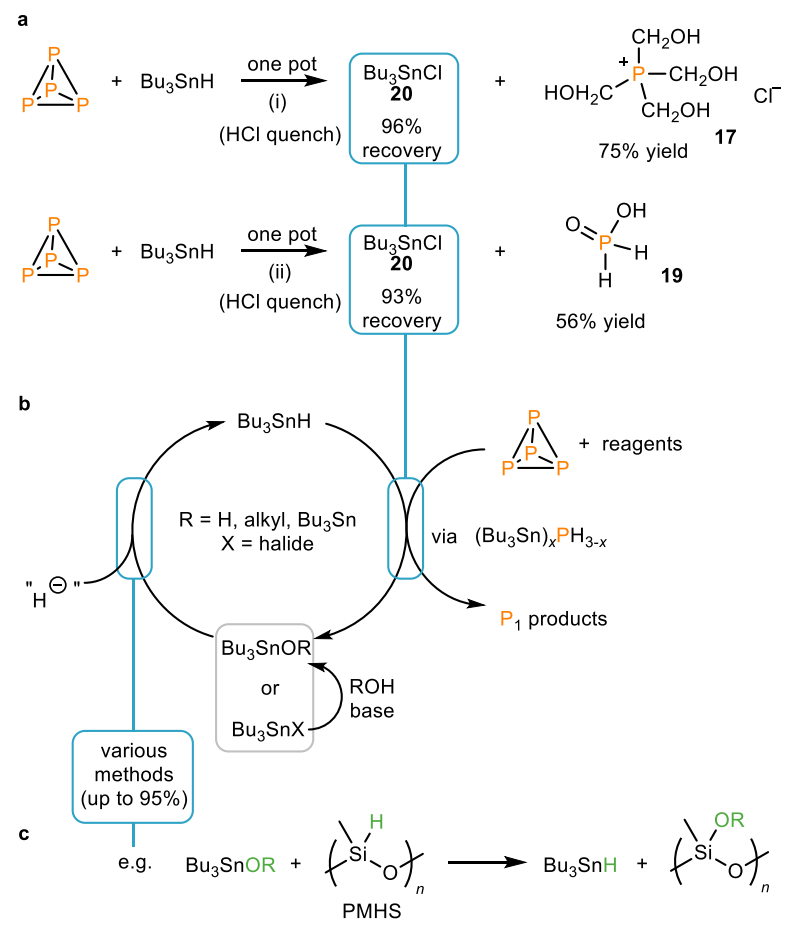

Figure 5. Recycling of the $\mathrm{Bu}_{3} \mathrm{Sn}$ moiety. a, Recovery of $\mathrm{Bu}_{3} \mathrm{SnCl}$ from the syntheses of THPC and HPA. b, An outline 'BusSn-neutral' synthetic cycle for transformation of $\mathrm{P}_{4}$ into monophosphorus species, through reduction of recovered $\mathrm{Bu}_{3} \mathrm{Sn}$ derivatives with hydride sources (see ref. 58). c, A specific example of regeneration of $\mathrm{Bu}_{3} \mathrm{SnH}$ using PMHS as hydride source. Conditions (equivalents, equiv., are here defined per $\mathrm{P}$ atom): (i) from $\mathrm{P}_{4}$ : 1.6 equiv. $\mathrm{Bu}_{3} \mathrm{SnH}, \mathrm{PhMe}, 455 \mathrm{~nm}$ LEDs, RT, $16 \mathrm{~h}$, then $-\mathrm{PhMe}, \mathrm{EtOH}, 12.5$ equiv. paraformaldehyde, $\mathrm{RT}, 16 \mathrm{~h}$, then 10 equiv. $\mathrm{HCl}$ (4.0 M in 1,4-dioxane), 
$\mathrm{RT}, 2 \mathrm{~h}$; (ii) from $\mathrm{P}_{4}$ : 1.6 equiv. $\mathrm{Bu}_{3} \mathrm{SnH}, \mathrm{PhMe}, 455 \mathrm{~nm}$ LEDs, $\mathrm{RT}, 16 \mathrm{~h}$, then 10 equiv. $\mathrm{H}_{2} \mathrm{O}_{2}(35 \%$ aq.), $\mathrm{RT}, 30$ min, then $\mathrm{H}_{2} \mathrm{O}, 2.5$ equiv. $\mathrm{HCl}$ (4.0 M in 1,4-dioxane).

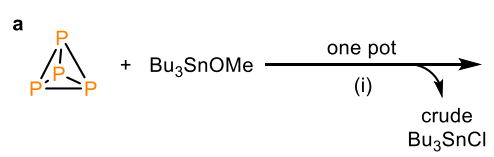

b

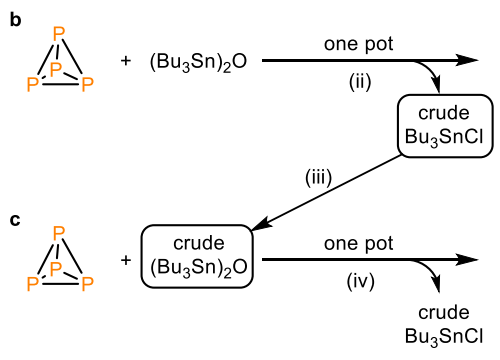

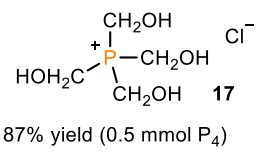

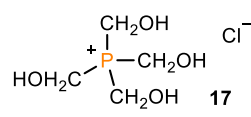

$88 \%$ yield $\left(0.5 \mathrm{mmol}_{4}\right)$

$80 \%$ yield $\left(5 \mathrm{mmol} \mathrm{P}_{4}\right)$

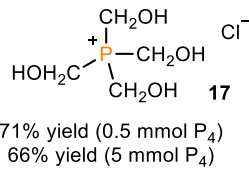

Figure 6. Synthesis of THPC (17) via in situ generation of $\mathrm{Bu}_{3} \mathrm{SnH}$. One pot synthesis of THPC starting directly from $\mathrm{P}_{4}$ and $\mathbf{a}, \mathrm{Bu}_{3} \mathrm{SnOMe}$ or $\mathbf{b},\left(\mathrm{Bu}_{3} \mathrm{Sn}\right)_{2} \mathrm{O}$. c, Direct recycling of the $\mathrm{Bu}_{3} \mathrm{Sn}$ moiety without re-isolation of any intermediate $\mathrm{Bu}_{3} \mathrm{SnX}$. Conditions (equivalents, equiv., are here defined per $\mathrm{P}$ atom): (i) from $\mathrm{P}_{4}: 2$ equiv. Bu $3 \mathrm{SnOMe}^{2} 2$ equiv. PMHS, PhMe, $455 \mathrm{~nm}$ LEDs, RT, $16 \mathrm{~h}$, then -PhMe, EtOH, 12.5 equiv. paraformaldehyde, RT, 16 h, then 10 equiv. $\mathrm{HCl}$ (4.0 M in 1,4-dioxane), RT, 2 h; (ii) from $\mathrm{P}_{4}: 1$ equiv. $\left(\mathrm{Bu}_{3} \mathrm{Sn}\right)_{2} \mathrm{O}, 5$ mol\% ACN, 2 equiv. $\mathrm{PMHS}, \mathrm{PhMe}$, dark, $80^{\circ} \mathrm{C}, 3 \mathrm{~d}$, then $-\mathrm{PhMe}, \mathrm{EtOH}$, 12.5 equiv. paraformaldehyde, $\mathrm{RT}, 16 \mathrm{~h}$, then 10 equiv. $\mathrm{HCl}$ (4.0 $\mathrm{M}$ in 1,4-dioxane), $\mathrm{RT}, 2 \mathrm{~h}$; (iii) from crude $\mathrm{Bu}_{3} \mathrm{SnCl}$ : sat. $\mathrm{Na}_{2} \mathrm{CO}_{3}$ (aq.), RT, 16 h; (iv) from $\mathrm{P}_{4}$ : 1 equiv. crude $\left(\mathrm{Bu}_{3} \mathrm{Sn}\right)_{2} \mathrm{O}, 5$ mol\% ACN, 2 equiv. PMHS, PhMe, dark, $80^{\circ} \mathrm{C}, 3 \mathrm{~d}$, then -PhMe, EtOH, 12.5 equiv. paraformaldehyde, RT, $16 \mathrm{~h}$, then 10 equiv. $\mathrm{HCl}$ (4.0 M in 1,4-dioxane), $\mathrm{RT}, 2 \mathrm{~h}$.

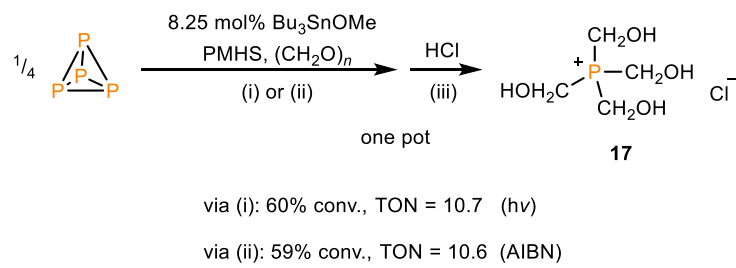

Figure 7. Synthesis of THPC (17) via catalytic transformation of $P_{4}$ into THP (16). Turnover numbers (TON) are calculated from the measured conversion (conv.) to THPC and factor in the 1:6 stoichiometry of the $\mathrm{P}_{4}$ hydrostannylation reaction, as described in Supplementary Methods 30 and 31 . Conv. and TON values are based upon an average of two runs. Catalyst/initiator loadings (mol\%) and molar equivalents (equiv.) are defined per $\mathrm{P}$ atom. Conditions: (i) $8.3 \mathrm{~mol} \% \mathrm{Bu} 3 \mathrm{SnOMe}, 4$ equiv. PMHS, 8.3 equiv. paraformaldehyde, EtOH/PhH (2:1), 365 nm LEDs, RT, 65 h; (ii) 8.3 mol\% Bus $\mathrm{SnOMe} 8$ 
equiv. PMHS, 8.3 equiv. paraformaldehyde, $8.3 \mathrm{~mol} \% \mathrm{AIBN}, \mathrm{EtOH} / \mathrm{PhH}(2: 1), 60^{\circ} \mathrm{C}, 65 \mathrm{~h}$; (iii) 3.3 equiv. $\mathrm{HCl}$ (4.0 M in 1,4-dioxane), RT, $1 \mathrm{~h}$.

\section{Methods}

Herein can be found general experimental information, and representative experimental procedures for key reactions. Those procedures not described below can instead be found in the Supplementary Information, alongside relevant characterisation data.

Note: $P_{4}$ is toxic and highly pyrophoric and should be handled, manipulated and quenched with corresponding caution.

\section{General information}

Unless stated otherwise, all reactions and manipulations were performed under an $\mathrm{N}_{2}$ atmosphere $\left(<0.1 \mathrm{ppm} \mathrm{O}_{2}, \mathrm{H}_{2} \mathrm{O}\right)$ through use of MBraun Unilab and GS MEGA Line gloveboxes, and standard Schlenk line techniques. All glassware was oven-dried $\left(160{ }^{\circ} \mathrm{C}\right)$ overnight prior to use. $\mathrm{PhH}$ and DME were distilled from Na/benzophenone and stored over molecular sieves (3 $\AA$ ). MeCN was distilled from $\mathrm{CaH}_{2}$ and stored over molecular sieves $(3 \AA)$. $n$-Pentane was distilled from $\mathrm{Na}$ and stored over K. $n$-Hexane was purified using an MBraun SPS-800 system and stored over $\mathrm{K}$. PhMe, $\mathrm{Et}_{2} \mathrm{O}$ and THF were purified using an MBraun SPS800 system and stored over molecular sieves ( $3 \AA$ ). EtOH was degassed and dried by standing over at least three sequential batches of molecular sieves $(3 \AA) . C_{6} D_{6}$ was distilled from $K$ and stored over molecular sieves $(3 \AA) . \mathrm{CD}_{3} \mathrm{CN}, \mathrm{CD}_{3} \mathrm{OD}$ and $\mathrm{D}_{2} \mathrm{O}$ were used without purification. All reagents and starting materials were purchased from major suppliers. Liquids were degassed (if not supplied under inert atmosphere) but were otherwise used as supplied, unless stated otherwise. $\mathrm{Bu}_{3} \mathrm{SnH}$ was supplied containing $0.05 \% \mathrm{BHT}$ as stabilizer and was used as received. $\mathrm{Bu}_{3} \mathrm{SnOMe}$ and $\mathrm{PMHS}$ were degassed and stored over molecular sieves ( $3 \AA$ ). $\mathrm{PhBr}$ was distilled and degassed. $\left(\mathrm{Bu}_{3} \mathrm{Sn}\right)_{2} \mathrm{O}, \mathrm{NEt}_{3}$ and $\mathrm{BnBr}$ were distilled, degassed, and stored over molecular sieves (3 $\AA$ ). $\mathrm{H}_{2} \mathrm{O}_{2}$ (ca. $35 \%$ ) was used as supplied. Solids were dried under vacuum (with the exception of paraformaldehyde and $\mathrm{Na}_{2} \mathrm{CO}_{3}$ ) but otherwise used as supplied, 
unless stated otherwise. $\mathrm{P}_{4}$ was sublimed prior to use. $\mathrm{P}_{5} \mathrm{Ph}_{5}$ was prepared in accordance with the literature. ${ }^{62}$

NMR spectra were recorded at room temperature on Bruker Avance $400(400 \mathrm{MHz})$ spectrometers and were processed using Topspin 3.2. Chemical shifts, $\delta$, are reported in parts per million (ppm); ${ }^{1} \mathrm{H}$ NMR and ${ }^{13} \mathrm{C}$ NMR shifts are reported relative to $\mathrm{SiMe}_{4}$ and were referenced internally to residual solvent peaks, while ${ }^{31} \mathrm{P}$ and ${ }^{119} \mathrm{Sn}$ NMR shifts were referenced externally to $85 \% \mathrm{H}_{3} \mathrm{PO}_{4}$ (aq.) and $\mathrm{SnMe}_{4}\left(90 \%\right.$ in $\left.\mathrm{C}_{6} \mathrm{D}_{6}\right)$, respectively. Except where stated otherwise, integrals for ${ }^{31} \mathrm{P}\left\{{ }^{1} \mathrm{H}\right\}$ and ${ }^{31} \mathrm{P}$ spectra are provided for the purposes of qualitative comparison only, and should not be considered quantitatively accurate. The abbreviations s, d, t, q, m are used to indicate singlets, doublets, triplets, quartets and multiplets, respectively. Mass spectrometry was performed by the analytical department of the University of Regensburg using Jeol AccuTOF GCX and Agilent Q-TOF 6540 UHD spectrometers.

Reactions driven by light were performed using apparatus that has been illustrated in a previous publication, ${ }^{21}$ in which reaction vessels are illuminated from beneath by LEDs while placed in a metal block through which cooling water is constantly circulated to maintain nearambient temperature.

\section{Hydrostannylation of $\mathrm{P}_{4}$ using $\mathrm{Bu}_{3} \mathrm{SnH}$ under blue LED irradiation ( $0.01 \mathrm{mmol}$ scale)}

To a $10 \mathrm{~mL}$, flat-bottomed, stoppered tube were added PhMe $(500 \mu \mathrm{L}), \mathrm{P}_{4}(0.01 \mathrm{mmol}$, as a stock solution in $79.6 \mu \mathrm{L} \mathrm{PhH})$ and $\mathrm{Bu}_{3} \mathrm{SnH}(16.1 \mu \mathrm{L}, 0.06 \mathrm{mmol})$. The tube was sealed, placed in a water-cooled block to maintain near-ambient temperature, and irradiated with blue light (455 nm ( $\pm 15 \mathrm{~nm}), 3.2 \mathrm{~V}, 700 \mathrm{~mA}$, Osram OSLON SSL 80$)$ for $18 \mathrm{~h}$. The resulting mixture was analysed by ${ }^{1} \mathrm{H},{ }^{31} \mathrm{P}\left\{{ }^{1} \mathrm{H}\right\},{ }^{31} \mathrm{P}$ and ${ }^{119} \mathrm{Sn}\left\{{ }^{1} \mathrm{H}\right\}$ NMR spectroscopy, as shown in Extended Data Figs. 1-4.

Of the four product resonances observed in the ${ }^{31} \mathrm{P}\left\{{ }^{1} \mathrm{H}\right\}$ spectrum, the most downfield is readily identified as belonging to $\mathrm{PH}_{3}(\mathbf{1})$ on the basis of both chemical shift $(-242.0 \mathrm{ppm})$ and the characteristic quartet splitting (with large $\left.{ }^{1} \mathrm{~J}^{31}{ }^{1} \mathrm{P}_{-}{ }^{1} \mathrm{H}\right)=186.5 \mathrm{~Hz}$ ) of the corresponding signal in 
the proton-coupled ${ }^{31} \mathrm{P}$ spectrum. ${ }^{3}$ The remaining signals are consistent with the products $\left(\mathrm{Bu}_{3} \mathrm{Sn}\right)_{x} \mathrm{PH}_{3-x}(x=1-3 ; 2-4$, respectively $)$, with larger $x$ leading to increasingly upfield resonances. These assignments are consistent with the upfield chemical shifts reported for similar triorganotin-substituted phosphines, ${ }^{37}$ with the multiplicities observed in the corresponding proton-coupled ${ }^{31} \mathrm{P}$ spectrum (as well as the magnitude of the ${ }^{1} \mathrm{~J}\left({ }^{31} \mathrm{P}-{ }^{1} \mathrm{H}\right.$ ) coupling constants), with the presence and relative intensities of observed ${ }^{117 / 119} \mathrm{Sn}$ satellites (as well as the magnitude of the corresponding coupling constants), and with the absence of any observable ${ }^{31} \mathrm{P}-{ }^{31} \mathrm{P}$ couplings.

Spectra for analogous reactions performed using $n$-hexane, $\mathrm{PhH}, \mathrm{Et}_{2} \mathrm{O}$, THF or DME in place of PhMe gave very similar NMR spectra. For illustration, the ${ }^{31} \mathrm{P}\left\{{ }^{1} \mathrm{H}\right\}$ spectra are shown in Extended Data Fig. 5.

\section{Synthesis and isolation of $\mathrm{P}(\mathrm{C}(\mathrm{O}) \mathrm{tBu})_{3}(8)$}

To a $50 \mathrm{~mL}$ flat-bottomed Schlenk were added $\mathrm{P}_{4}(62.0 \mathrm{mg}, 0.5 \mathrm{mmol})$ and $\mathrm{PhMe}(25 \mathrm{~mL})$. After stirring to obtain a homogeneous solution $\mathrm{Bu}_{3} \mathrm{SnH}$ was added $(847 \mu \mathrm{L}, 3.15 \mathrm{mmol})$. The resulting colorless solution was stirred under irradiation with blue LED light (7X Osram OSLON SSL80, $455 \mathrm{~nm}( \pm 15 \mathrm{~nm}), 20.3 \mathrm{~V} 1000 \mathrm{~mA})$ for $22 \mathrm{~h}$, during which time the Schlenk tube was placed in a block cooled by circulating water to maintain near-ambient temperature. $t \mathrm{BuC}(\mathrm{O}) \mathrm{Cl}$ $(979 \mu \mathrm{L}, 8.0 \mathrm{mmol})$ and KHMDS $(599 \mathrm{mg}, 3.0 \mathrm{mmol})$ were added, the Schlenk tube was immediately and thoroughly wrapped in Al foil to exclude any ambient light, and the reaction mixture was stirred at room temperature for $16 \mathrm{~h}$. The resulting light yellow suspension was filtered, and volatiles were removed under vacuum. The remaining white residue was recrystallized from $\mathrm{n}$-hexane at $-35^{\circ} \mathrm{C}$, to afford the desired product as colourless needles (325 mg, 57\%). For characterisation data, see Supplementary Method 18.

\section{Synthesis and isolation of $\left[\mathrm{Bn}{ }_{4} \mathrm{P}\right] \mathrm{Br}(14)$ (with KHMDS)}

To a $50 \mathrm{~mL}$ flat-bottomed Schlenk were added $\mathrm{P}_{4}(62.0 \mathrm{mg}, 0.5 \mathrm{mmol})$, PhMe $(25 \mathrm{~mL})$, and $\mathrm{Bu}_{3} \mathrm{SnH}(847 \mu \mathrm{L}, 3.15 \mathrm{mmol})$. The resulting homogeneous, colorless solution was stirred under 
irradiation with blue LED light (7X Osram OSLON SSL80, 455 nm ( $\pm 15 \mathrm{~nm}), 20.3 \mathrm{~V}$ 1000mA) for $22 \mathrm{~h}$, during which time the Schlenk tube was placed in a block cooled by circulating water to maintain near-ambient temperature. Benzyl bromide $(2.4 \mathrm{~mL}, 20 \mathrm{mmol})$ and KHMDS (399 mg, $2.0 \mathrm{mmol}$ ) were added and the reaction mixture heated to $60{ }^{\circ} \mathrm{C}$ with stirring for 3 days. After cooling to room temperature the pale yellow suspension was evaporated to dryness, and the resulting solid was washed with pentane $(2 \times 20 \mathrm{~mL})$ and extracted with acetone ( 4 × $15 \mathrm{~mL}$; undried, 'bench' acetone was used). Removal of volatiles under vacuum yielded the target product as a white solid $(775 \mathrm{mg}, 82 \%)$. For characterisation data, see Supplementary Method 24.

\section{Synthesis and isolation of THPC (17) via hydrostannylation under blue LEDs in PhMe, with recovery of $\mathrm{Bu}_{3} \mathrm{SnCl}(20)$}

To a $50 \mathrm{~mL}$ flat-bottomed Schlenk tube were added $\mathrm{P}_{4}(62.0 \mathrm{mg}, 0.5 \mathrm{mmol})$ and $\mathrm{PhMe}(25 \mathrm{~mL})$. After stirring to obtain a homogeneous solution, $\mathrm{Bu}_{3} \mathrm{SnH}(847 \mu \mathrm{L}, 3.15 \mathrm{mmol})$ was added. The resulting colourless, homogeneous mixture was stirred under irradiation with blue LED light (7X Osram OSLON SSL80, $455 \mathrm{~nm}( \pm 15 \mathrm{~nm}), 20.3 \mathrm{~V} 1000 \mathrm{~mA})$ for $16 \mathrm{~h}$, during which time the Schlenk tube was placed in a block cooled by circulating water to maintain near-ambient temperature. Following removal of volatiles under vacuum, EtOH $(25 \mathrm{~mL})$ and paraformaldehyde $(750 \mathrm{mg}, 25 \mathrm{mmol}$ ) were added, and the resulting suspension was stirred at room temperature for $16 \mathrm{~h}$. The mixture was frozen in a liquid nitrogen bath and $\mathrm{HCl}(4.0 \mathrm{M}$ in 1,4-dioxane, $5 \mathrm{~mL}, 20 \mathrm{mmol}$ ) was added. After thawing, the reaction mixture was stirred at room temperature for $2 \mathrm{~h}$. The yellowish suspension was filtered, and volatiles were removed under vacuum. The remaining oily solid residue was triturated with $\mathrm{Et}_{2} \mathrm{O}(20 \mathrm{~mL})$ overnight, filtered and washed with further $\mathrm{Et}_{2} \mathrm{O}(20 \mathrm{~mL})$ to afford the desired product as a white solid (281 mg, 75\%) after drying under vacuum.

The combined $\mathrm{Et}_{2} \mathrm{O}$ washes from the above reaction were dried under vacuum to afford $\mathrm{Bu}_{3} \mathrm{SnCl}(20)$ as a pale yellow oil $(987 \mathrm{mg}, 96 \%)$. For characterisation data of both isolated products, see Supplementary Method 30. 


\section{Synthesis and isolation of HPA (19), with recovery of $\mathrm{Bu}_{3} \mathrm{SnCl}(20)$}

To a $50 \mathrm{~mL}$ flat-bottom Schlenk tube were added $\mathrm{P}_{4}(62.0 \mathrm{mg}, 0.5 \mathrm{mmol})$ and $\mathrm{PhMe}(25 \mathrm{~mL})$. After stirring to obtain a homogeneous solution, $\mathrm{Bu}_{3} \mathrm{SnH}(847 \mu \mathrm{L}, 3.15 \mathrm{mmol})$ was added. The resulting colourless, homogeneous mixture was stirred under irradiation with blue LED light (7X Osram OSLON SSL80, $455 \mathrm{~nm}( \pm 15 \mathrm{~nm}), 20.3 \mathrm{~V} 1000 \mathrm{~mA})$ for $16 \mathrm{~h}$, during which time the Schlenk tube was placed in a block cooled by circulating water to maintain near-ambient temperature. The resulting solution was frozen in a liquid nitrogen bath and $\mathrm{H}_{2} \mathrm{O}_{2}(35 \%$ aq., $0.43 \mathrm{~mL}, 5.0 \mathrm{mmol}$ ) was added. After thawing, the reaction mixture was stirred at room temperature for 30 minutes. Subsequent work-up was performed under air. $\mathrm{H}_{2} \mathrm{O}(20 \mathrm{~mL})$ was added and, after mixing thoroughly, the organic phase was separated and washed with further $\mathrm{H}_{2} \mathrm{O}(3 \times 15 \mathrm{~mL})$. Volatiles were removed under vacuum, and $n$-hexane $(20 \mathrm{~mL})$ and $\mathrm{MeCN}$ $(20 \mathrm{~mL})$ were added. $\mathrm{HCl}$ was added dropwise to the stirred biphasic mixture $(4.0 \mathrm{M}$ in 1,4dioxane, $1.25 \mathrm{~mL}, 5 \mathrm{mmol}$ ), and after stirring for $1 \mathrm{~h}$ the $\mathrm{MeCN}$ layer was separated and volatiles were removed under vacuum. The resulting colourless oil was washed with further nhexane $(20 \mathrm{~mL})$ and dried thoroughly under vacuum to yield the desired product as a colourless oil (127 mg, 57\%). The material obtained in this manner typically contains ca. $10 \% \mathrm{HP}(\mathrm{O})(\mathrm{OH})_{2}$ (as judged by ${ }^{31} \mathrm{P}\left\{{ }^{1} \mathrm{H}\right\}$ NMR spectroscopy), which is a known oxidation product of $\mathrm{H}_{2} \mathrm{P}(\mathrm{O}) \mathrm{OH} .{ }^{56}$ In order to ascertain the $\mathrm{H}_{2} \mathrm{O}$ content, quantitative ${ }^{31} \mathrm{P}\left\{{ }^{1} \mathrm{H}\right\}$ NMR spectroscopic analysis (D1 = $14 \mathrm{~s}$ ) was performed on a $\mathrm{CD}_{3} \mathrm{CN}$ solution containing precisely known quantities of both this product $(6.5 \mathrm{mg})$ and $\mathrm{Ph}_{3} \mathrm{PO}(23.0 \mathrm{mg})$, with the latter acting as an internal standard for integration. In this manner the precise amount of HPA (and $\mathrm{HP}(\mathrm{O})(\mathrm{OH})_{2}$ ) in the sample could be calculated, with the remaining mass being attributed to $\mathrm{H}_{2} \mathrm{O}$. The overall composition was thus determined to be $\mathrm{HPA} \cdot\left(\mathrm{HP}(\mathrm{O})(\mathrm{OH})_{2}\right)_{0.14} \cdot\left(\mathrm{H}_{2} \mathrm{O}\right)_{1.92}$, and this composition was used to calculate the isolated yield.

The combined $n$-hexane washes from the above reaction were dried under vacuum to afford $\mathrm{Bu}_{3} \mathrm{SnCl}(20)$ as a pale yellow oil (953 $\left.\mathrm{mg}, 93 \%\right)$. For characterisation data of both isolated products, see Supplementary Method 35. 


\section{Synthesis and isolation of THPC (17) via hydrostannylation starting from $\left(\mathrm{Bu}_{3} \mathrm{Sn}\right)_{2} \mathrm{O}$, with recycling of $\mathrm{Bu}_{3} \mathrm{SnCl}(20)(5 \mathrm{mmol}$ scale)}

To a $500 \mathrm{~mL}$ round-bottomed Schlenk flask were added $\mathrm{P}_{4}(620 \mathrm{mg}, 5 \mathrm{mmol})$ and $\mathrm{PhMe}$ $(250 \mathrm{~mL})$. After stirring to obtain a homogeneous solution, $\left(\mathrm{Bu}_{3} \mathrm{Sn}\right)_{2} \mathrm{O}(10.2 \mathrm{~mL}, 20 \mathrm{mmol})$, PMHS (2.3 mL, $40 \mathrm{mmol})$ and ACN (244 mg, $1 \mathrm{mmol}$ ) were added. The Schlenk flask was immediately and thoroughly wrapped in Al foil to exclude any ambient light, and the stirred reaction mixture was then heated to $80{ }^{\circ} \mathrm{C}$ for 3 days. Following removal of volatiles under vacuum, $\mathrm{EtOH}(250 \mathrm{~mL})$ and paraformaldehyde $(7.51 \mathrm{~g}, 250 \mathrm{mmol})$ were added, and the resulting suspension was stirred at room temperature for $16 \mathrm{~h}$. The mixture was frozen in a liquid nitrogen bath and $\mathrm{HCl}(4.0 \mathrm{M}$ in 1,4-dioxane, $50 \mathrm{~mL}, 200 \mathrm{mmol})$ was added. After thawing, the reaction mixture was stirred at room temperature for $4 \mathrm{~h}$. The pale yellow suspension was filtered through a bed of Celite in a glass frit (P4) column, and volatiles were removed under vacuum. The remaining oily solid residue was triturated with $\mathrm{Et}_{2} \mathrm{O}(200 \mathrm{~mL})$ overnight, filtered and washed with further $\mathrm{Et}_{2} \mathrm{O}(2 \times 25 \mathrm{~mL})$. The resulting white solid was then again extracted into $\mathrm{EtOH}(2 \times 100 \mathrm{~mL})$. Following filtration and removal of volatiles under vacuum, the desired product was obtained as a white solid $(3.05 \mathrm{~g}, 80 \%)$.

NMR data are identical to those reported in Supplementary Method 30.

To the combined $\mathrm{Et}_{2} \mathrm{O}$ washes from the above reaction was added a saturated aqueous solution of $\mathrm{Na}_{2} \mathrm{CO}_{3}(150 \mathrm{~mL})$. The resulting biphasic mixture was stirred under open bench conditions for $24 \mathrm{~h}$, and the organic phase was separated and washed with $\mathrm{H}_{2} \mathrm{O}(4 \times 100 \mathrm{~mL})$. The organic phase was transferred into a $500 \mathrm{~mL}$ Schlenk flask and volatiles were removed under vacuum. The remaining procedure was performed under an inert atmosphere. A solution of $\mathrm{P}_{4}(620 \mathrm{mg}, 5 \mathrm{mmol})$ pre-dissolved in PhMe $(250 \mathrm{~mL})$ was added, followed by PMHS $(2.3 \mathrm{~mL}, 40 \mathrm{mmol})$ and $\mathrm{ACN}(244 \mathrm{mg}, 1 \mathrm{mmol})$. The Schlenk tube was immediately and thoroughly wrapped in Al foil to exclude any ambient light, and the stirred reaction mixture was then heated to $80^{\circ} \mathrm{C}$ for 3 days. Following removal of volatiles under vacuum, $\mathrm{EtOH}(250 \mathrm{~mL})$ and paraformaldehyde $(7.51 \mathrm{~g}, 250 \mathrm{mmol})$ were added, and the resulting suspension was 
stirred at room temperature for $16 \mathrm{~h}$. The mixture was frozen in a liquid nitrogen bath and $\mathrm{HCl}$ (4.0 $\mathrm{M}$ in 1,4-dioxane, $50 \mathrm{~mL}, 200 \mathrm{mmol}$ ) was added. After thawing, the reaction mixture was stirred at room temperature for $4 \mathrm{~h}$. The yellowish suspension was filtered through a bed of Celite in a glass frit (P4) column, and volatiles were removed under vacuum. The remaining oily solid residue was triturated with $\mathrm{Et}_{2} \mathrm{O}(200 \mathrm{~mL})$ overnight, filtered and washed with further Et2O $(2 \times 25 \mathrm{~mL})$. The resulting white solid was then again extracted into EtOH $(2 \times 100 \mathrm{~mL})$. Following filtration and removal of volatiles under vacuum, the desired product was obtained as a white solid $(2.52 \mathrm{~g}, 66 \%)$.

NMR data are identical to those reported in Supplementary Method 30.

\section{Catalytic hydrostannylation of $\mathrm{P}_{4}$ using $\mathrm{Bu}_{3} \mathrm{SnOMe}$ and PMHS under near UV irradiation}

To a $10 \mathrm{~mL}$, flat-bottomed, stoppered Schlenk tube were added $\mathrm{EtOH}(500 \mu \mathrm{L}), \mathrm{P}_{4}(0.03 \mathrm{mmol}$, as a stock solution in $232 \mu \mathrm{L} \mathrm{PhH}), \mathrm{Bu}_{3}$ SnOMe $(2.9 \mu \mathrm{L}, 0.01 \mathrm{mmol})$, PMHS $(28.7 \mu \mathrm{L}$, $0.48 \mathrm{mmol}$ ) and paraformaldehyde (30 $\mathrm{mg}, 1.0 \mathrm{mmol})$. The tube was sealed, placed in a watercooled block to maintain near-ambient temperature, and irradiated with near UV (365 nm) LEDs for $65 \mathrm{~h}$. The mixture was then frozen in a liquid nitrogen bath and $\mathrm{HCl}(4.0 \mathrm{M}$ in 1,4dioxane, $0.1 \mathrm{~mL}, 0.4 \mathrm{mmol}$ ) was added. After thawing, the reaction mixture was stirred at room temperature for $1 \mathrm{~h}$. Following addition of $\mathrm{Ph}_{3} \mathrm{PO}(0.04 \mathrm{mmol}$, as a stock solution in $506 \mu \mathrm{L}$ $\mathrm{MeCN}$ ) as an internal standard, the resulting mixture was analysed by ${ }^{31} \mathrm{P}\left\{{ }^{1} \mathrm{H}\right\} \mathrm{NMR}$ spectroscopy, as shown in Supplementary Fig. 136. The chemical shift observed for THPC (17) in these spectra is ca. $1 \mathrm{ppm}$ downfield of that observed in spectra of isolated samples, which is attributed to solvent effects and the presence of excess $\mathrm{HCl}$. That these peaks correspond to THPC was unambiguously confirmed by subsequent addition of an authentic sample to one representative reaction, which clearly increased the intensity of this peak.

Accurate conversion to THPC was measured by integration of a single-scan, inverse-gated ${ }^{31} \mathrm{P}\left\{{ }^{1} \mathrm{H}\right\}$ NMR spectrum (Supplementary Fig. 137), in line with our previously-described methodology. ${ }^{21}$ For two independent runs, conversions of $57 \%$ and $62 \%$ were determined. 
Turnover numbers (TONS; 10.2 and 11.2, respectively, for an average of 10.7) were calculated from these conversions by factoring in the 1:6 stoichiometry of the reaction between $\mathrm{P}_{4}$ and $\mathrm{Bu}_{3} \mathrm{SnH}$. Because of this stoichiometry, full consumption of 1 eq. of $\mathrm{P}_{4}$ relative to $\mathrm{Bu}_{3} \mathrm{SnOMe}$ requires six turnovers of the catalyst (i.e. it must be used to regenerate $\mathrm{Bu}_{3} \mathrm{SnH}$ six times). Equivalently, formation of 1 eq. of THPC (from 0.25 eq. P4) requires 1.5 turnovers of the catalyst. The TON is therefore calculated as 1.5 times the molar ratio between the THPC formed and the $\mathrm{Bu}_{3} \mathrm{SnOMe}$ catalyst employed.

\section{References (methods)}

62. Barnard, J. H., Brown, P. A., Shuford, K. L. \& Martin, C. D. 1,2-Phosphaborines: hybrid inorganic/organic P-B analogues of benzene. Angew. Chem. Int. Ed. 54, 12083-12086 (2015).

\section{Data availability}

The authors declare that the data supporting the findings of this study are available within the paper (and its Supplementary Information files). 